\title{
Papers
}

\section{Salt-related problems in brick masonry and electrokinetic removal of salts}

Received (in revised form): 22nd June, 2007

\section{Lisbeth M. Ottosen}

is Associate Professor at Department of Civil Engineering, Technical University of Denmark (DTU). She obtained a $\mathrm{PhD}$ in remediation of heavy metal polluted soil using an applied electric field (in 1996, Department of Geology and Geotechnical Engineering \& Department of Physical Chemistry, DTU) and her research focus has since then been laid on the utilisation of electrokinetic transport processes in civil and environmental engineering. She is the author of more than 50 scientific journal papers.

\section{Anne J. Pedersen}

is an experienced researcher within the field of utilising electrochemical transport mechanisms for removal of contaminants from porous materials. She obtained her PhD from the Department of Civil Engineering, Technical University of Denmark, on the topic: 'Electrochemical removal of heavy metals from fly ashes' (2002), and during 2002-2006 she worked as research assistant professor at the department, still focusing on utilising electrochemical transport processes in environmental and civil engineering.

\section{Inge Rörig-Dalgaard}

is a PhD student at Department of Civil Engineering, Technical University of Denmark (DTU). In 2002 she started to work with electrochemical transport processes (master project) as a method for water transport in building materials. During 2002-2004 she was working as an assistant researcher in the field of electrochemistry applied on soil and building materials. Since 2004 she has been working on her PhD project, which focuses on ion transport in building constructions by use of electrochemistry.

Correspondence: Lisbeth M. Ottosen, Department of Civil Engineering, Building 118, Technical University of Denmark, Lyngby 2800, Denmark; Tel: + 45452522 60; Fax: +45 458832 82; E-mail: lo@byg.dtu.dk

\begin{abstract}
When newly plastered masonry facades show dark moist areas at a certain height or the plaster is loose from the masonry, the problem is often linked to increased salt content within the masonry. In the first case, the salts result in hygroscopic moisture and in the latter the salts are precipitating in the interface between the plaster and the masonry resulting in the plaster loosing adhesion. High salt concentrations can further result in salt weathering of masonry where the brick and/or mortar are/is seriously damaged. There is a lack of proven methods for the removal of salts from masonry. In the present paper, it is shown in laboratory and by a small pilot test that it is possible to remove the salt by applying an electric DC field to the masonry. Very low salt concentrations can be obtained in the laboratory, but the method needs further development before it can be used in actual buildings. The pilot test did show that salts can be removed from real salt contaminated masonry. Journal of Building Appraisal (2007) 3, 181-194. doi:10.1057/palgrave.jba.2950074
\end{abstract}

\section{Keywords:}

brick masonry, chlorides, nitrates, electrokinetics

\section{INTRODUCTION}

Rising dampness is a source of salts in masonry. The types and concentrations of salts found in/on building stone vary greatly and depend on the stone type and the environment 
around the building. The most common salts in masonry are sulphates, chlorides and nitrates (Perry and Duffy, 1997). The salts can originate from the soil, for example, in geological environments that have previously been part of the sea bed. De-icing salts spread close to a building during winter time can also be a source of salts, and in buildings near agricultural land or former stables, the masonry may contain high concentrations of nitrates originating from the decomposition of organic material.

The presence of aqueous electrolyte solutions in capillary pores of brick masonry can, under changing climate conditions, cause deterioration of wall structures due to the change between dissolved ions in solution and nucleated salt. Ions move in brick masonry depending on the water content, and salts may then be precipitated. Different types of damage may appear due to this concentrating phenomenon including:

- Bricks and mortar can decompose from salt-induced decay (Figure 1).

- If the masonry is covered with paint/plaster, precipitating salts can damage the adhesion (Figure 2).

- The presence of salts increases the hygroscopic moisture content of the masonry (Figure 3).

Since efficient methods for the removal of damaging salts from brick masonry are not available, there is a need for development of such methods. In the present paper, removal of chlorides and nitrates from brick masonry in an applied electric field is the main focus. Electrochemical techniques applied to concrete for repair and maintenance purposes are well known (eg cathodic protection and electrokinetic removal of chlorides), but very limited research has been published on the use of electrokinetics for the removal of salts from brick masonry. In the research presented here, experiments have been conducted on single bricks in the laboratory and a set of electrodes have been tested on a masonry wall of an old stable where hygroscopic moisture due to high nitrate concentrations is a pronounced problem.

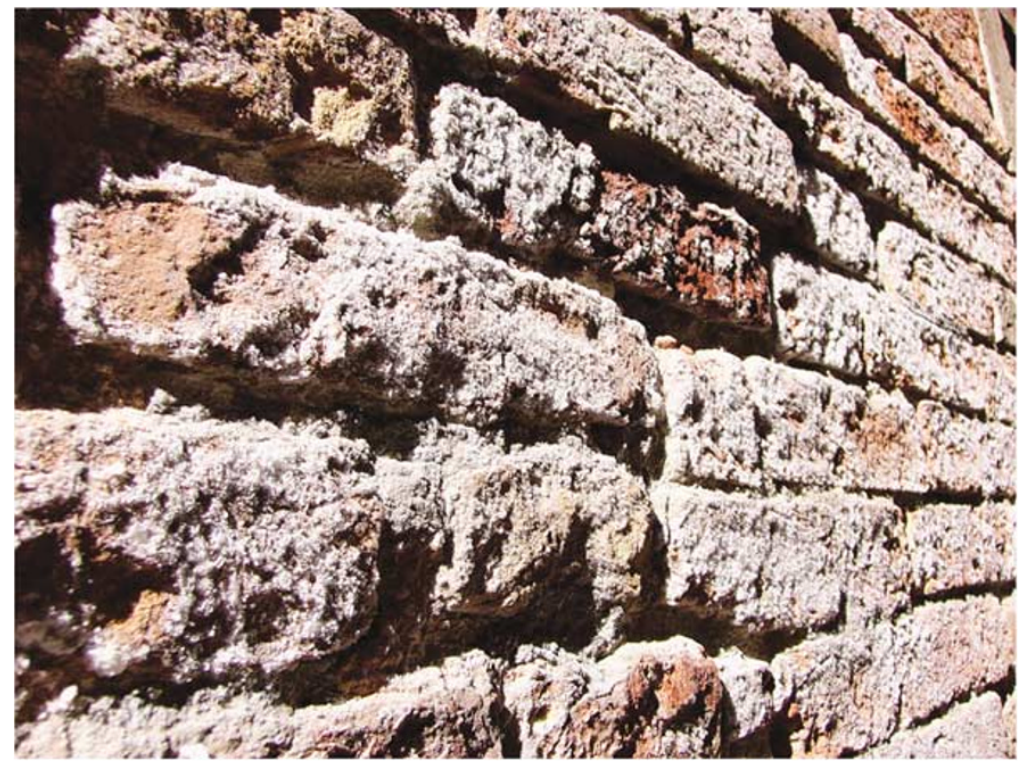

Figure I: Salt-induced decay of brick masonry can be seen by the rounded corners. Salts have precipitated on the surface of the masonry as effloresce 


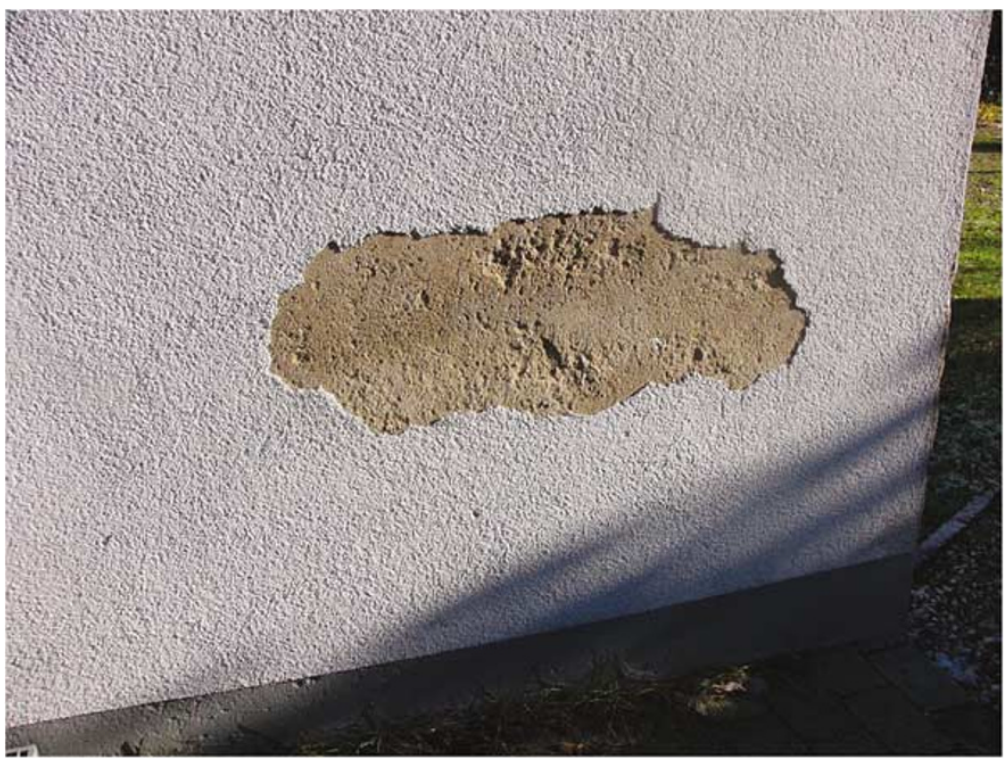

Figure 2: Adhesion of paint damaged by salts

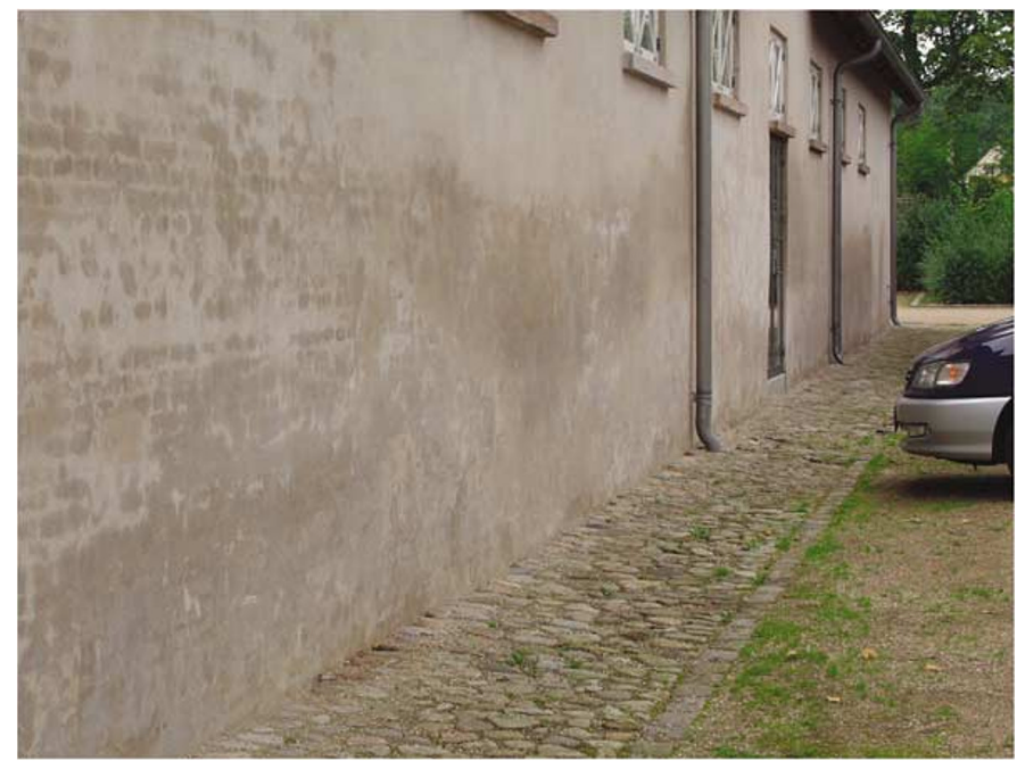

Figure 3: Hygroscopic moisture is seen as dark bands at a certain height

\section{DAMAGING CONCENTRATIONS OF SALTS IN MASONRY}

To evaluate the salt concentration in bricks in relation to hygroscopic moisture content, the Austrian ÖNORM B 3355-1 'Trockenlegung von Feuchtem Mauerwerk -

Bauwerksdiagnostik und Planungsgrundlagen' (Dehumidification of masonry - Building diagnostics and planning principles) are used in the present work as it is the only available source of threshold values at present. The salt concentrations are separated into three categories in this norm: 
For $\mathrm{NO}_{3}^{-}$:

$-<0.05$ per cent weight $(<0.5 \mathrm{~g} / \mathrm{kg})-$ no risk;

- $0.05-0.15$ per cent weight $(0.5-1.5 \mathrm{~g} / \mathrm{kg})$ - individual evaluation necessary;

$->0.15$ per cent weight $(>1.5 \mathrm{~g} / \mathrm{kg})$ - active salt removal advised.

For $\mathrm{Cl}^{-}$:

$-<0.03$ per cent weight $(<0.3 \mathrm{~g} / \mathrm{kg})-$ no risk;

- 0.03-0.10 per cent weight $(0.3-1.0 \mathrm{~g} / \mathrm{kg})$ - individual evaluation necessary;

$->0.10$ per cent weight $(>1.0 \mathrm{~g} / \mathrm{kg})$ - active salt removal advised.

\section{BASIC PRINCIPLES OF ELECTROKINETICS}

Below, a short introduction to the electrochemical processes needed in order to understand the principles of the electrokinetic salt removal process is given.

The main transport mechanism for the salt ions in the masonry in the applied electric

DC field is electromigration. Positive ions in the pore solution of the masonry will move towards the negative electrode and the negative ions will move towards the positive electrode. During the process, the salt concentration will decrease in the masonry and the ions will concentrate around the electrodes.

In metal electrodes, the electric current is carried by electrons but in the pore water the current is carried by ions (electromigration). The processes that transform the current carried by electrons to current carried by ions and vice versa are called electrode processes. Which electrode processes will occur depends on the electrode material, the applied potential and the type of ions in the pore water. Oxidation processes, however, always occur at the anode and reduction processes at the cathode.

In the experimental work of the present paper, two types of electrodes were used: iron electrodes and platinum-coated electrodes. In the laboratory scale experiments reported here, platinum-coated electrodes were used, but such electrodes are very expensive and hence we have chosen to use much cheaper iron electrodes in the pilot scale.

At the cathode, reaction (1) will be prevailing in both cases.

Cathode (negative electrode) process: $2 \mathrm{H}_{2} \mathrm{O}+2 \mathrm{e}^{-} \rightarrow 2 \mathrm{OH}^{-}+\mathrm{H}_{2}(\mathrm{~g})$

Depending on the electrode material and ions present in the vicinity of the anode, several electrode processes may occur. In the case of inert platinum-coated electrodes, reactions (2) and (3) will take place depending on prevailing $\mathrm{pH}$. In the case $\mathrm{of}^{-}$in the vicinity of the anode, process (4) is also likely to occur. In the case of iron anodes, reaction (5) will occur together with other reactions. Reaction (5) is corrosion of the iron anode.

Anode (positive electrode) processes: $2 \mathrm{OH}^{-} \rightarrow \mathrm{H}_{2} \mathrm{O}+1 / 2 \mathrm{O}_{2}(\mathrm{~g})+2 \mathrm{e}^{-}$

$$
\begin{gathered}
\mathrm{H}_{2} \mathrm{O} \rightarrow 2 \mathrm{H}^{+}+1 / 2 \mathrm{O}_{2}(\mathrm{~g})+2 \mathrm{e}^{-} \\
2 \mathrm{Cl}^{-} \rightarrow \mathrm{Cl}_{2}(\mathrm{~g})+2 \mathrm{e}^{-} \\
\mathrm{Fe}(\mathrm{s}) \rightarrow \mathrm{Fe}^{2+}(\mathrm{aq})+2 \mathrm{e}^{-}
\end{gathered}
$$


The electrode processes are influencing the environment around the electrodes. Around the cathode, the environment becomes alkaline due to production of hydroxyl ions and, around the anode, it becomes acidic due to the hydrogen ions formed. When designing the electrodes taking this into account is important.

Transport of water is also expected to occur in the masonry as a result of the applied electric field. This water movement is called electro-osmosis. Electro-osmosis is the movement of water in a porous medium in an applied electric field, and is likely to occur when the inner surfaces of the medium carry a certain charge. The charge is counterbalanced by ions in the electric double layer. The net flux of ions towards one of the electrodes pushes water molecules in the same direction. The inner surfaces of bricks are charged (Ottosen and Rörig-Dalgård, 2007) and electro-osmosis can occur in bricks. Electro-osmosis in clays is also a well-known phenomenon (Grundl and Michalski, 1996).

\section{ELECTRODE COMPOSITION}

When choosing the composition of the electrode units for the salt removal process from masonry, it is important that the acid $\left(\mathrm{H}^{+}\right)$produced at the anode is hindered in reaching the masonry because it will destroy the mortar. Electromigration of $\mathrm{OH}^{-}$ from the cathodic reaction into the brick may also be unwanted because an increase in $\mathrm{OH}^{-}$concentration results in a decrease in the transference number of anions to be removed (the transference number expresses how large a fraction of the current is carried by the actual ion). Such a decrease is seen in concrete where the transference number of chloride ions decreases during chloride extraction (Castelotte et al., 2000).

From electrokinetic soil remediation, it is known that an acidic front develops very slowly in calcareous soils (Ottosen et al., 2005) and due to this it was chosen to place the metallic electrodes in clay (from a tilework) with high carbonate content and place the clay on the surface of the brick/masonry. The clay contained 17-18 per cent carbonates in the experiments reported here. By this, the acid is hindered from entering the masonry since it is neutralised in the clay. When placing the electrodes in clay, it is also possible to remove the salts from the masonry after treatment by removing the clay as the salts concentrate in it because of the process.

\section{ANALYTICAL}

To the present investigation, the part of $\mathrm{NO}_{3}^{-}$and $\mathrm{Cl}^{-}$in the bricks/masonry of relevance is the water soluble fraction, and as such extractions in distilled water are made prior to measurement of concentrations. For the chemical analysis (laboratory experiments) the brick material was powdered in a mechanical mortar before the extractions and in the pilot-scale experiment the drilling powder was used directly for extractions. Extractions were made with $10 \mathrm{~g}$ dry powder and $25 \mathrm{ml}$ distilled water (for the bricks from laboratory experiments) and $1.0 \mathrm{~g}$ powder and $25 \mathrm{ml}$ water for the masonry. The suspensions were placed on a shaking table for $1 \mathrm{~h}$ and the $\mathrm{pH}$ was measured before filtration. After filtration the anion concentrations (chloride and nitrate) were measured by ion chromatography.

Water content was measured as weight loss at $105^{\circ} \mathrm{C}$ for $24 \mathrm{~h}$ (calculated as weight of water/dry weight). 


\section{LABORATORY EXPERIMENTS}

\section{Materials and methods}

To evaluate the potential for removing salts from bricks in an applied electric field, laboratory experiments were conducted. One electrokinetic experiment was conducted for the removal of each of chloride and nitrate. Reference experiments were conducted where no current was applied for comparison. The bricks used in the laboratory experiments were yellow and new from the factory of Wewers, Denmark, and had dimensions approximately $22.8 \times 10.8 \times 5.4 \mathrm{~cm}$. The bricks were broken into two pieces about $11.4 \times 10.8 \times 5.4 \mathrm{~cm}$, manually using a hammer and chisel. Electrokinetic and reference experiments were conducted with these half-bricks. The half-bricks were submerged in $\mathrm{NaCl}(15 \mathrm{~g} / \mathrm{L})$ or $\mathrm{NaNO}_{3}(22 \mathrm{~g} / \mathrm{L})$ for four days prior to the experiments.

After submerging the half-bricks in the salt solutions, electrodes with an electric DC field (10 mA for 9 days) were applied to one half and the other half was wrapped in plastic film and used as a reference.

The electrode units used in the laboratory experiments consisted of plexiglass tubes with an internal diameter of $8.0 \mathrm{~cm}$ and a length of $5.0 \mathrm{~cm}$. The ends of the tubes away from the brick were closed. In the upper side of the tubes, there were two holes as shown in Figure 4. The holes closest to the brick were closed during the experiments. In the outer holes, the electrodes were placed. They were bar electrodes (platinum coated) with a diameter of $3 \mathrm{~mm}$. The electrodes reached approximately $7 \mathrm{~cm}$ into the electrode compartment. At the top the electrodes, a stopper was placed to close the hole around the electrode.

The electrode compartments were filled with clay. The clay was supplied from the local brickwork, Wienerberger, Helsinge, Denmark, and was chosen due to the high carbonate content of about 17 per cent.

The experiments conducted were:

A. Reference experiment, $\mathrm{NaCl}$.

B. Electrokinetic experiment, $\mathrm{NaCl}$.

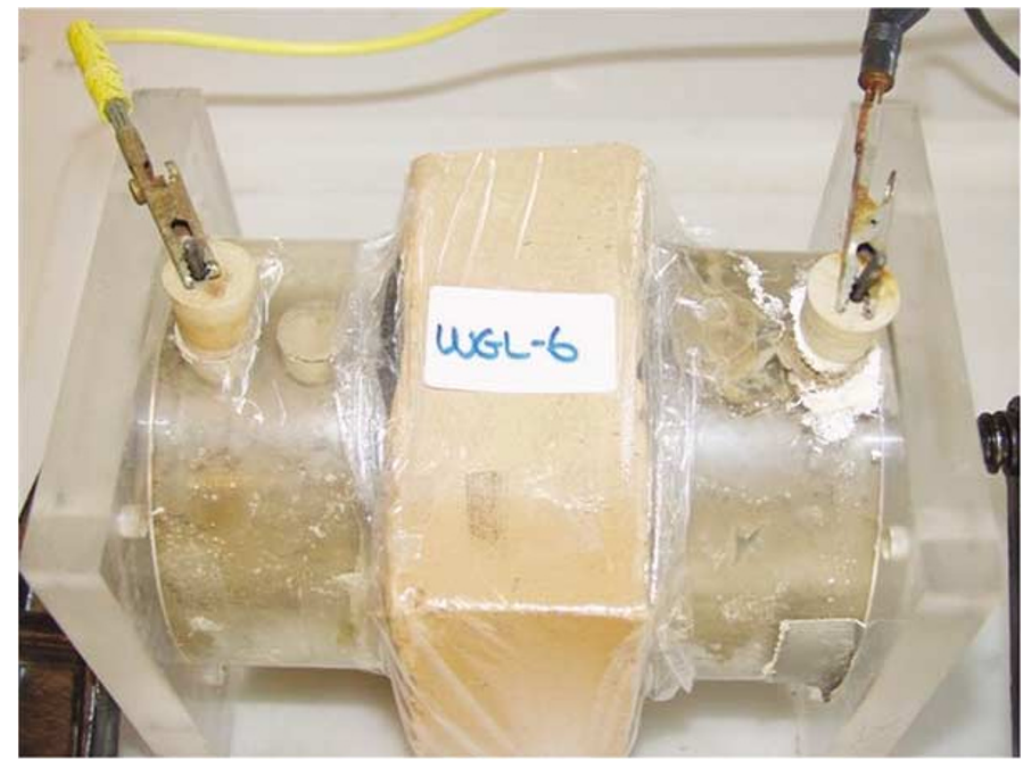

Figure 4: Laboratory set-up 
C. Reference experiment, $\mathrm{NaNO}_{3}$.

D. Electrokinetic experiment, $\mathrm{NaNO}_{3}$.

At the end of the experiments, the bricks were segmented into six pieces. At first each brick-half was broken into two parts, an upper part and a lower part, of approximately the same size (upper and lower relates to the position during the experiments). Then the upper as well as the lower part were segmented into three slices. One slice from each end next to the electrodes and one slice in between. The segmentation was done with hammer and chisel by hand. Each segment was crushed into smaller pieces by hand and then a mechanical mortar was used to crush the pieces into fine powder. The analysis of $\mathrm{Cl}^{-}$ and $\mathrm{NO}_{3}^{-}$were made with this powder.

\section{Results and discussion}

The concentrations of chloride and nitrate in the blind bricks and in the bricks after electrokinetic treatment are shown in Figure 5. The success rate of removal of chloride was very high, 99 per cent. For nitrate a similar high level of removal was obtained in the slice close to the cathode. In the middle slice, the rate was 98 per cent. In the slice closest to the anode, however, only 27 per cent of nitrates was removed. The nitrate ions were moving towards the anode but not all nitrate was removed from the brick into the clay at the anode during the experiment. In total 74 per cent of the nitrate was removed in experiment D.

In the clay at the anode the concentration of chloride and nitrate was 1,100 and $2,250 \mathrm{mg} / \mathrm{kg}$, respectively, at the end of experiments B and D. For comparison, concentrations in the clay at the cathode were $9 \mathrm{mg} / \mathrm{kg}$ and $130 \mathrm{mg}^{-} / \mathrm{kg}$ for chloride and nitrate, respectively. This is a clear indication that electromigration of these two anions is in the direction towards the anode.

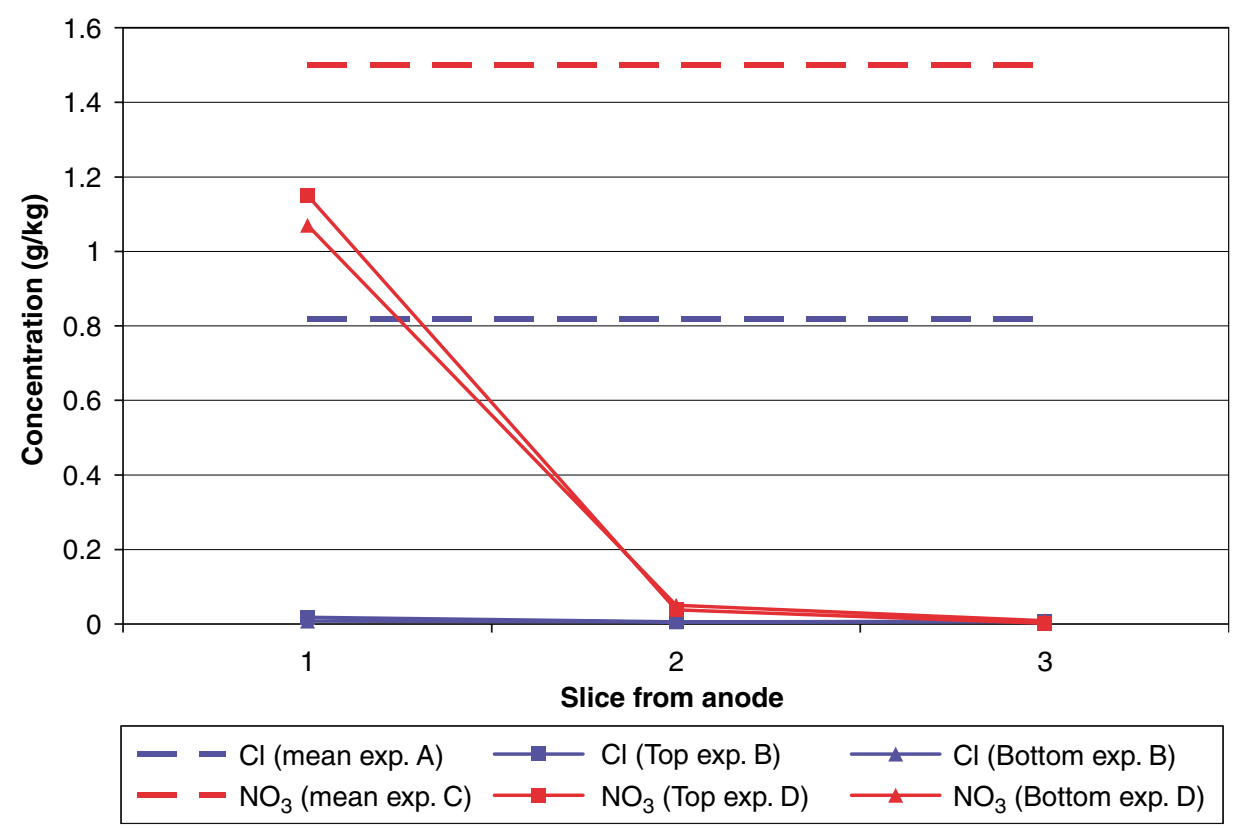

Figure 5: Chloride and nitrate concentrations in brick slices. A + C: reference bricks, $B+D$ : electrokinetic treatment 
In comparison with the values from ÖNORM B 3355-1, the initial chloride concentration $0.83 \mathrm{~g} \mathrm{Cl} / \mathrm{kg}$ (represented by blind brick A) was at a level where individual evaluation is advised. The initial nitrate concentration (represented by blind brick $\mathrm{C}$ ) was $1.5 \mathrm{~g} \mathrm{NO}_{3}^{-} / \mathrm{kg}$ which is exactly the value where salt removal is advised. The final chloride concentration obtained in experiment $\mathrm{B}$ was $\leqslant 0.02 \mathrm{mg} \mathrm{Cl} / \mathrm{kg}$, which is considered a harmless concentration. The nitrate concentration obtained in slices 2 and 3 in experiment D was similarly low, at $\leqslant 0.05 \mathrm{mg} / \mathrm{kg}$, although the concentration did not decrease sufficiently in the whole brick. As the electrical resistance between the electrodes reached high levels, this problem will not be solved simply by leaving it for longer time. Optimisation of the current and voltage is, therefore, necessary in the case of nitrate removal. It should also be noted that the current and voltage reached in the laboratory are unrealistically high compared to those that would be possible with electrodes attached to a masonry wall, but the experiments did show that it is possible to remove nitrate and chloride from bricks in an applied electric field.

\section{PILOT-SCALE EXPERIMENT}

\section{Locality description and initial investigation}

On the basis of the promising laboratory results, it was decided to test a single set of electrodes on a masonry wall of an old stable that was severely contaminated with salts (Figure 3). The stable was used to house the horses of the cavaliers connected to Bernstorff Palace, Gentofte, Denmark. The stable was probably built at the same time as the Palace, in 1765. The present stable looks constructed in late 1800s, not earlier. It is likely, however, that the newer building is built on the old plinths and that some of the masonry was reused. Today the building is used as a conference centre and the surface of the masonry is covered with plaster. The experiment was made on the north side of the building which has a visible moisture problem (Figure 3) and which is never in direct sunlight.

Initially masonry samples were taken from the points where the electrodes were to be placed. Samples were taken at nine positions, $0.5-2.0 \mathrm{~m}$ above ground level. At each position, a sample of both brick and mortar was collected, giving 18 samples in total. The samples were taken in two rows $1.5 \mathrm{~m}$ apart. One row was $2.5 \mathrm{~m}$ from the corner (to the right in Figure 3) and the second row was $4.0 \mathrm{~m}$ from the corner. Between the sample rows there was an area that appeared very moist and here an extra sample was taken at a height of $1.25 \mathrm{~m}$. Samples were drilled with a power drill with a $5.0 \mathrm{~mm}$ drill bit to a depth of $3 \mathrm{~cm}$ and the dust from the bore holes was carefully collected for the analysis. The $\mathrm{Cl}^{-}$and $\mathrm{NO}_{3}{ }^{-}$concentrations at different heights and rows of sampling are shown at Figure 6. In comparison with the salt concentrations from the ÖNORM B 3355-1 (given above), it can be seen that the highest limiting concentration for $\mathrm{Cl}^{-}, 1.0 \mathrm{~g} / \mathrm{kg}$, is exceeded in a few samples. The brick sample taken in the middle of the moist area (at $3.75 \mathrm{~m}$ ) is the one containing the most $\mathrm{Cl}^{-}$. Most of the samples did, however, have $\mathrm{NO}_{3}^{-}$ concentrations that far exceeded the highest limiting value of $1.5 \mathrm{~g} / \mathrm{kg}$. The highest concentration measured was again in the brick from the moist area and was $11 \mathrm{~g} / \mathrm{kg}$. The high nitrate concentrations are consistent with the fact that the building is an old stable.

As the most visible areas of moisture are not at ground level but rather are higher up on the wall, this indicates that the moisture problem is of a hygroscopic nature due to the high salt concentrations. Figure 7 shows the relationship between the sum of chloride and nitrate concentrations, and the water content. It is clearly seen that there is a tendency for higher water content in samples with higher concentrations of the two anions which is an 

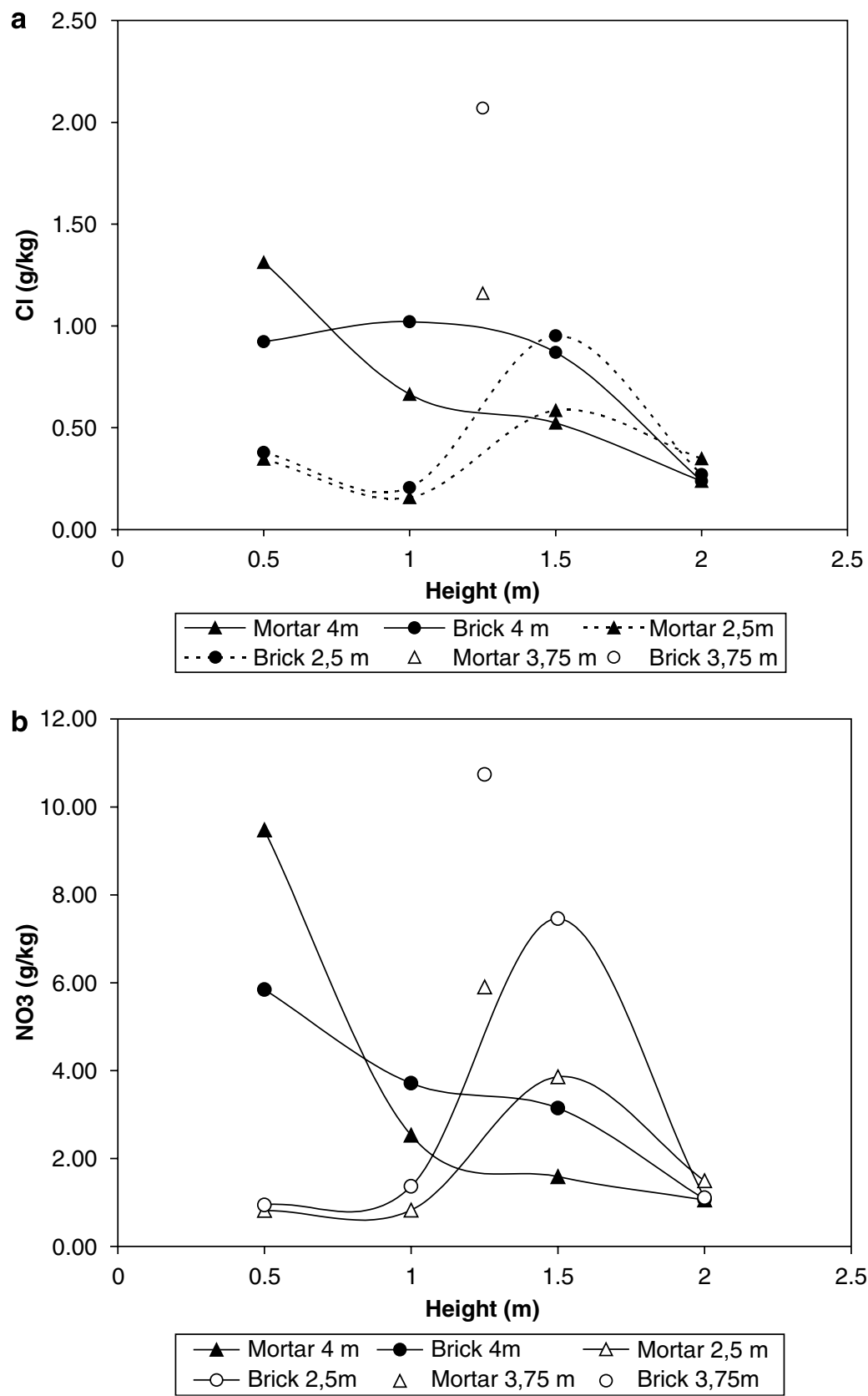

Figure 6: (a) Chloride and (b) nitrate concentrations in the stable masonry wall at different depths and distances from the corner

indication for hygroscopic moisture. The moisture problem of this masonry may thus be solved by removing the salts.

\section{The electrodes and experimental parameters}

The first set of electrodes was placed on the experimental wall in January 2006. All together, three sets of electrodes were used and they were placed in the same position on the wall. The electrodes were constructed utilising the same principle of using clay as a 


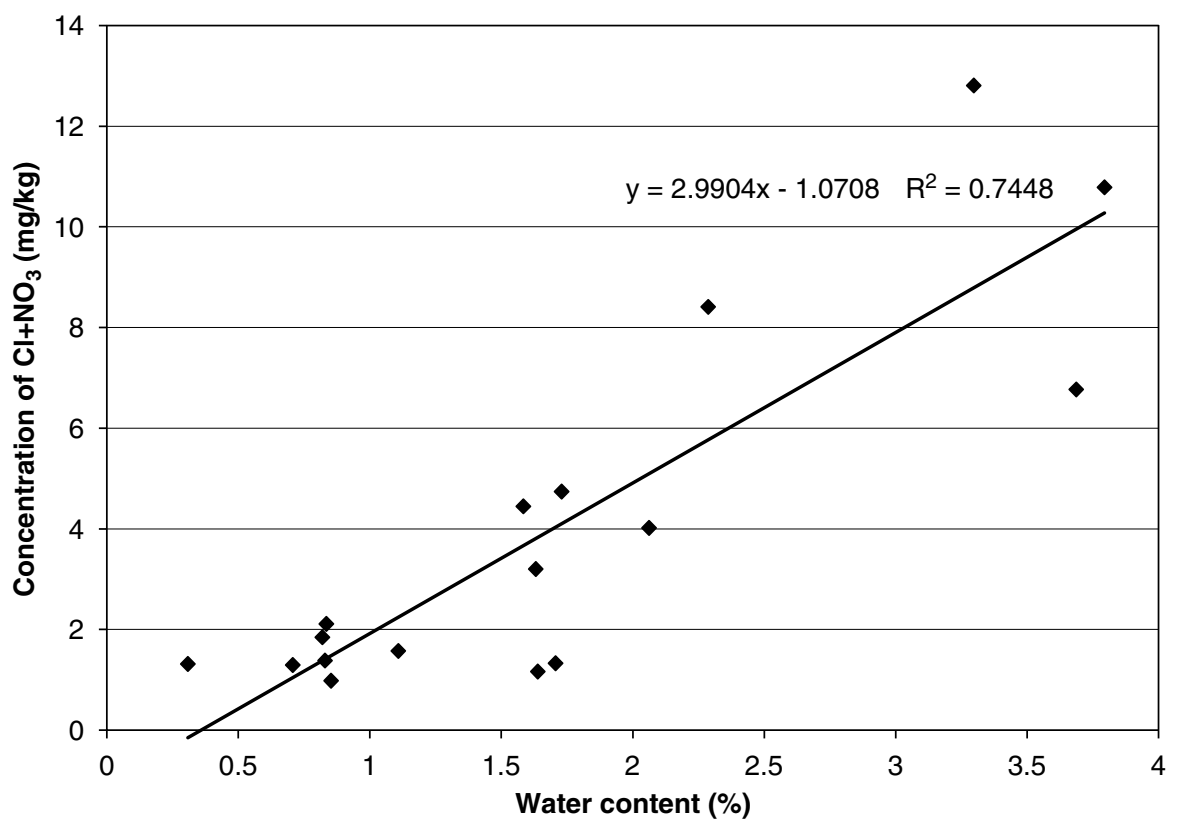

Figure 7: Relation between the sum of nitrate and chloride concentrations and water content in samples from experimental masonry

neutraliser as demonstrated in the laboratory experiments. The metallic electrodes were $1.5 \mathrm{~m}$ long rebars with the diameter of $6 \mathrm{~mm}$ (in the laboratory cells inert electrodes with a platinised surface were used, but such electrodes are too expensive for larger scale). Between the metal and the wall was approximately $1 \mathrm{~cm}$ of clay and to cover the rebar on the outer surface there was about $1 \mathrm{~cm}$ of clay. The clay had a water content of about 20 per cent and was relatively sticky, so it was easy to attach to the wall, which was done carefully by hand (Figure $8(\mathrm{a})$ ). The upper $5 \mathrm{~cm}$ of rebar was without clay cover, and it was here the electrodes were connected to the power supply. The distance between the electrodes was about $35 \mathrm{~cm}$.

For the first set of electrodes, the outer clay surfaces of electrodes were covered with plastic to avoid evaporation of water from the clay with a subsequent increased electric resistance. For the next two sets of electrodes, plastic film was used to decrease the extent to which evaporation occurred. A board was pressing the electrodes towards the wall during the experiments as it can be seen in Figure 8(b) through the plastic tent which was built to protect the electrodes from rain and snow.

It was decided to run the pilot experiment with application of a constant current as in the laboratory experiments, but at a much lower current density. The current applied was $40 \mathrm{~mA}$. Furthermore, the current was automatically turned off for $2 \mathrm{~h}$ every $24 \mathrm{~h}$ to hinder the build up of strong concentration gradients that may cause a significant increase in electric resistance. The duration of the experiment with the different electrode-pairs was:

$-1: 7$ days;

- 2: 35 days;

- 3: 42 days.

Between the experiments, the electrodes (clay and rebar) were removed and changed and the clay was analysed. In experiment 1 , only three clay samples from each electrode were 

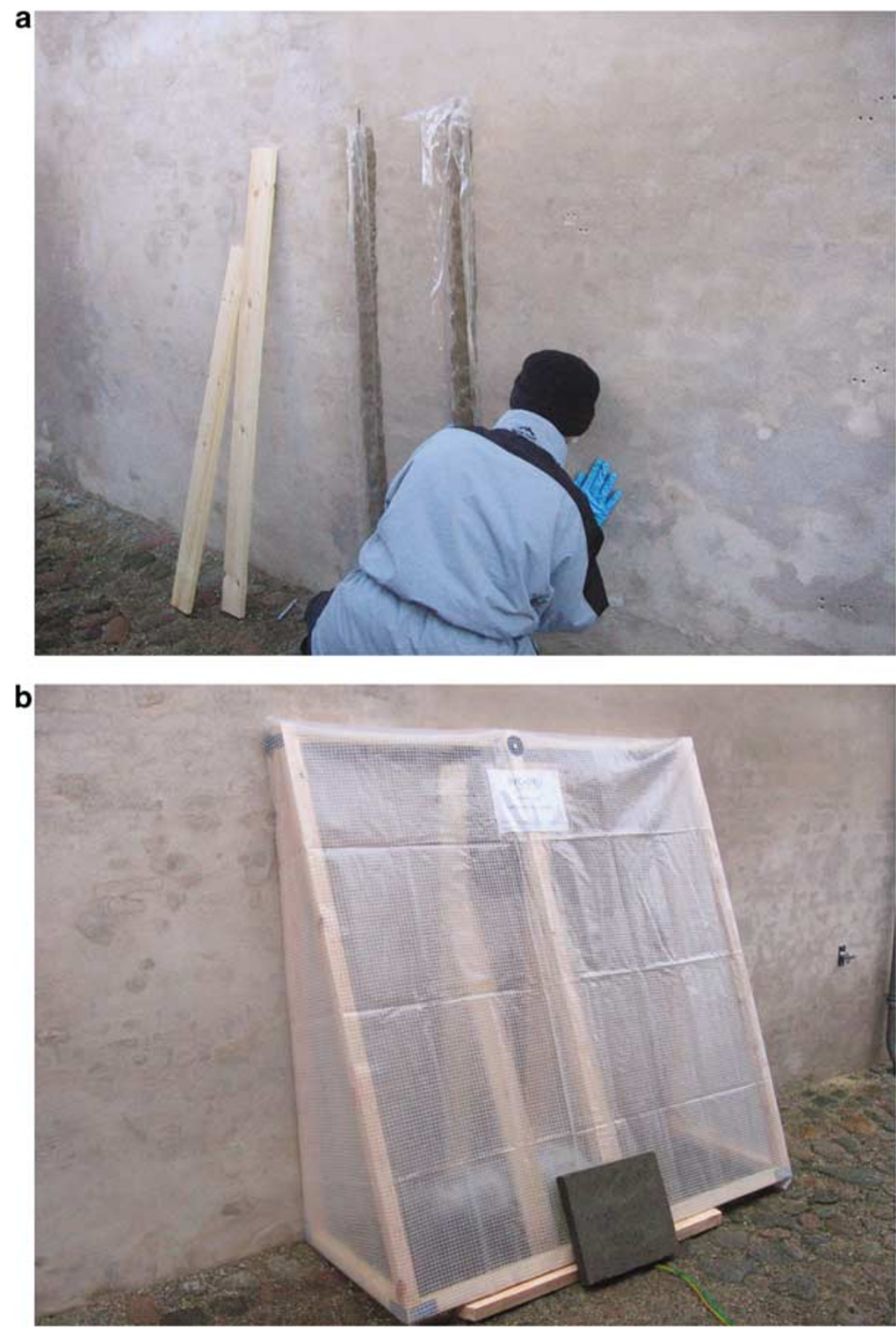

Figure 8: (a) The electrodes are placed at the masonry wall and (b) a tent protects the electrodes from rain and snow

taken $(0.2 \mathrm{~m} ; 0.75$ and $1.3 \mathrm{~m}$ from ground surface) but for the next two experiments, samples were taken every $10 \mathrm{~cm}$.

\section{Results and discussion}

In the present paper the first experiences with the pilot plant (three sets of electrodes) based on the analysis of chloride and nitrate concentrations in the clay surrounding the electrodes are reported. The pilot plant was running at the time of finishing this paper.

\section{Operational aspects}

Between installation of the first set of electrodes on the wall and switching on the current, seven days had passed, which was shown to be inappropriate since the clay at the 
electrodes had dried visibly. The voltage increased from 11 to $136 \mathrm{~V}$ (ie resistance had increased) during these seven days and then the electrodes were removed. The high electrical resistance between the electrodes was ascribed to the dry clay at the electrodes that caused poor electric connection between the clay and masonry. The water content of the clay is hence regarded an important parameter. For the next two experiments, the current was switched on immediately after the electrodes were placed on the wall, which showed to be an improvement, since the voltage increased only from about 12 to $60 \mathrm{~V}$ during the 35 days and to about $95 \mathrm{~V}$ during the 45 days of experiments 1 and 2 .

The outdoor temperature was around $0^{\circ} \mathrm{C}$ at the time of the experiment with this first set of electrodes. For the second set of electrode tests, the outdoor temperature was as low as $-10^{\circ}$ to $-15^{\circ} \mathrm{C}$ at night and the temperature was below $0^{\circ} \mathrm{C}$ during most of this experiment and shows that the salt removal process can occur even during periods of intense frost. The reason why the water in the clay did not freeze could be the small production of heat from the passage of current, but it can also be due to the constant movement of ions (electromigration) in the water that hinders the freezing process. The electrical resistance must be expected to be lower in the system at higher temperatures, but the result that electrokinetic salt removal can occur during winter is an important result.

\section{Changes in $\mathrm{pH}$, water content, nitrate and chloride concentrations}

The mean water content decreased significantly in the clay (initially 20 per cent) at both the anode and the cathode during all three experiments (see Table 1), probably mainly due to evaporation. The decrease in water content is expected to be a major problem to the process since this directly leads to an increase in resistivity between the electrodes and subsequently to increased costs and limited duration of operability of the process. The resistivity increases in the clay itself, but electric contact between clay and wall worsens. A solution must be found for this and it may include continuous addition of moisture to the interface between the wall and the clay.

The $\mathrm{pH}$ of the clay (initially 9.5) was highly influenced by the electrode processes since it increased at the cathode and decreased at the anode (see Table 1). $\mathrm{pH}$ in the clay from the anodes was, however, not acidic but remained neutral, which shows that neutralisation of the produced acid by calcium carbonates in the clay was successful.

The mean concentrations of nitrate and chloride were much higher in the clay at the anodes than in the clay at the cathodes for all three sets of electrodes which clearly show that electromigration was transporting these two anions out from the masonry into the clay. This result is of major importance to future work since it proves that the system works.

Figure 9 shows the profiles of nitrate and chloride at different heights in the clay of the anodes for the three experiments. It is seen that there are significant variations in

Table I: Mean values of water content, $\mathrm{pH}$ chloride and nitrate concentrations in the clay samples from the electrodes

\begin{tabular}{lllccc}
\hline & Electrode pair & Water content (\%) & pH & Chloride $(\mathrm{mg} / \mathbf{k g})$ & Nitrate $(\mathrm{mg} / \mathrm{kg})$ \\
\hline \multirow{2}{*}{ Anode } & $1^{*}$ & 14.1 & 8.0 & 1,450 & 4,200 \\
& $2^{\dagger}$ & 14.1 & 7.7 & 2,100 & 4,200 \\
& $3^{\dagger}$ & 9.1 & 7.9 & 1,620 & 3,300 \\
\multirow{4}{*}{ athode } & $1^{*}$ & 13.5 & 9.1 & 176 & 240 \\
& $2^{\dagger}$ & 15.1 & 10.0 & 15 & 10.1 \\
& $3^{\dagger}$ & 14.3 & 10.8 & 5.9 & 9.2 \\
\hline
\end{tabular}

*Three samples

† 14 samples 

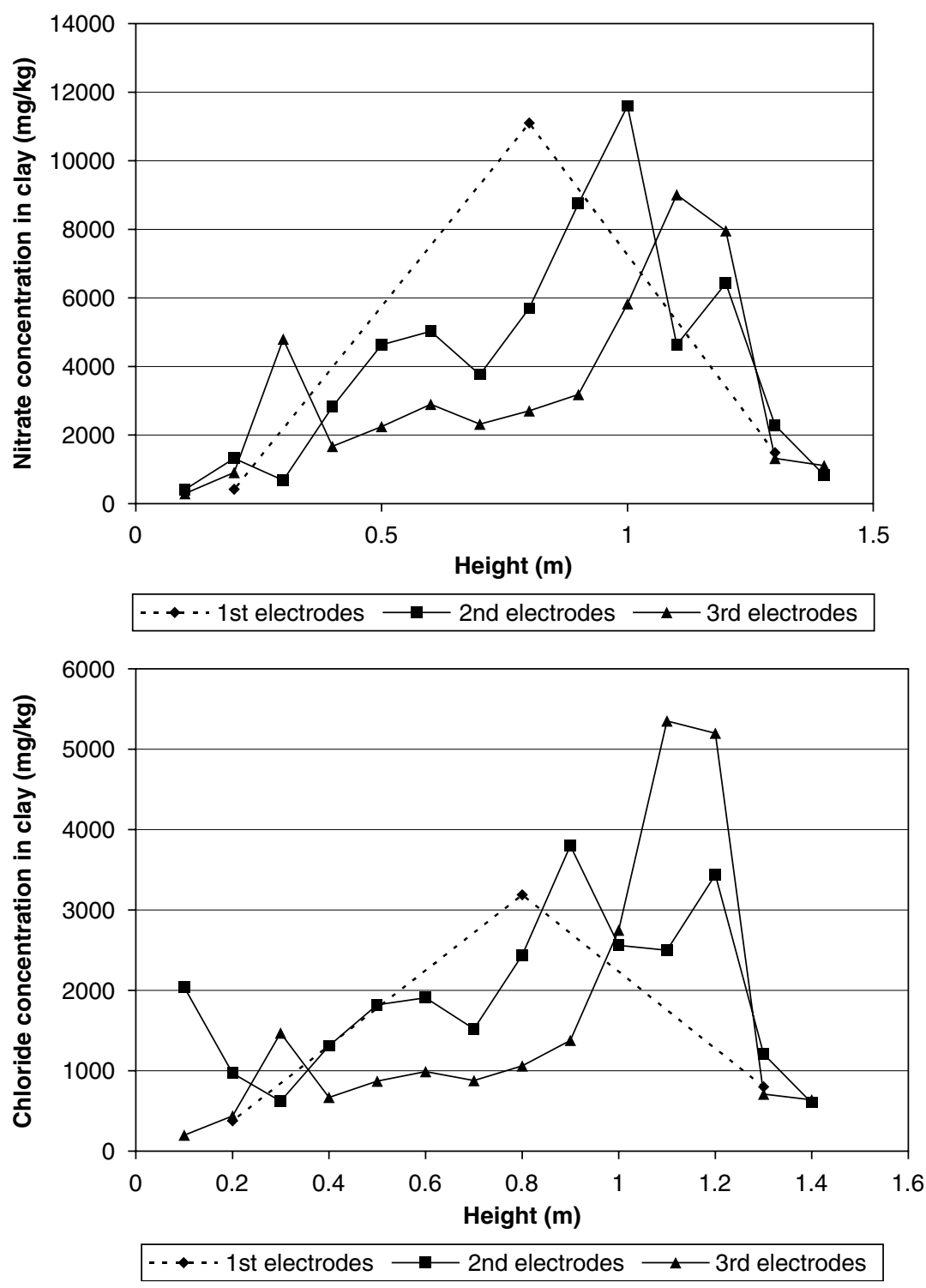

Figure 9: Nitrate and chloride concentrations in the clay from the anodes in the three experiments

concentrations in each experiment. In general, the concentrations were lower at the top and at the bottom of the anodes than in between. The highest nitrate concentrations obtained are higher than the highest chloride concentrations corresponding to the higher concentration of nitrate in the masonry (Figure 6). In the masonry, however, the concentration of chloride is only $1 / 10$ of the nitrate concentration and in the anode clay chloride concentration is $1 / 3$ to $1 / 2$ of the nitrate concentration. This finding may be related to the higher mobility of chloride in the applied electric field as it was found in the laboratory experiments.

Looking at the shape of the concentration profiles in the anode clay the first experiment cannot be considered since there are only three points. Except for the very bottom of anodes 2 and 3, the two concentration profiles have the same shape which is an indication of where the current density has been highest (where the highest concentrations are 
found) rather than related to the concentrations in the masonry since the highest concentrations are found at different heights in the two experiments.

In general, there seems to be a decreasing effectiveness of the removal of nitrate and chloride in the applied electric field. The duration is increasing from experiment 1 to 3 , but the amount removed (found in the anode-clay) decreased. One factor important to this finding could be a decreasing concentration of the anions in the masonry, but during experiments 2 and 3, nitrate removed was about $20 \mathrm{~g}$ and chloride was $10 \mathrm{~g}$ which is only a part of what is found in the masonry between the electrodes, so this is not the major cause. On the contrary, the produced $\mathrm{OH}^{-}$ions from the electrode process at the cathode are considered of major importance to the decreasing effectiveness. These $\mathrm{OH}^{-}$ions are more mobile than nitrate and chloride ions in the applied electric field and take over more and more of the transport of current as the concentration of $\mathrm{OH}^{-}$ions increases all through the experiments. From chloride removal from concrete in an applied electric field, it is well known that $\mathrm{OH}^{-}$ions have this negative effect, see, for example, Castelotte et al. (2000). In future testing, the cathode must be constructed in a way $\mathrm{OH}^{-}$ions from the electrode process are hindered from reaching the masonry.

\section{CONCLUSIONS}

We have shown that it is possible to remove chlorides and nitrates from bricks in the laboratory using an applied electric DC field. The initial salt concentrations in the bricks would have been considered problematic but after electrokinetic treatment nonproblematic salt concentrations were achieved.

Electrokinetic removal of salts from the masonry of an old stable wall was trialled and it was seen from preliminary results that here both chlorides and nitrates were removed from the masonry. The electrode construction must, however, be improved in comparison to what was tested. The two major problems to consider are (1) avoiding drying of the clay that surrounds the metallic electrodes in order to keep a good electrical contact between the metal and masonry all through the process, and (2) hindering the $\mathrm{OH}^{-}$ions that are produced from the electrode process at the cathode from reaching the masonry, since these ions become a major current carrier instead of the ions salt in focus.

\section{Acknowledgements}

Willum Kann Rasmussen Fonden is acknowledged for financial support for the laboratory experiments, and the Danish Palaces and Properties Agency is acknowledged for collaboration and financial support for the pilot experiment.

\section{References}

Castelotte, M., Andrade, C. and Alonso, C. (2000) 'Electrochemical removal of chlorides: modelling of the extraction, resulting profiles and determination of the efficient time of treatment', Cement and Concrete Research, 30, 615-621.

Grundl, T. and Michalski, P. (1996) 'Electroosmotically driven water flow in sediments', Water Research, 30(4), 811-818.

Ottosen, L.M., Pedersen, A.J., Ribeiro, A.B. and Hansen, H.K. (2005) 'Case study on the strategy and application of enhancement solutions to improve remediation of soils contaminated with $\mathrm{Cu}, \mathrm{Pb}$ and $\mathrm{Zn}$ by means of electrodialysis', Engineering Geology, 77, 317-329.

Ottosen, L.M. and Rörig-Dalgård, I. (2007) 'Electrokinetic removal of $\mathrm{Ca}\left(\mathrm{NO}_{3}\right)_{2}$ from bricks to avoid salt induced decay', Electrochimica Acta, 52(10), 3454-3463.

Perry, S.H. and Duffy, A.P. (1997) 'The short-term effects of mortar joints on salt movement in stone', Atmospheric Environment, 31(9), 1297-1305. 